\title{
Karakteristik Akustik Ruang Sidang Jurusan Fisika FMIPA-ITS sebagai Ruang Konferensi
}

\author{
Suyatno* dan Susilo Indrawati \\ Jurusan Fisika- FMIPA, Institut Teknologi Sepuluh Nopember Kampus ITS Sukolilo, Surabaya 60111
}

\begin{abstract}
Intisari
Nilai parameter akustik yang dibutuhkan sebuah ruang konferensi adalah kekerasan suara serta kejernihan suara yang diterima oleh masing-masing peserta. Untuk mendapatkan kuantifikasi parameter tersebut, diperlukan pengukuran distribusi parameter akustik meliputi SPL, C80, D50, dan RT. Pengukuran distribusi SPL dilakukan dengan menggunakan sumber suara berupa white noise dari loudspeaker yang ditempatkan di posisi pimpinan (depan) dan penerima (dalam hal ini mikrofon) di area penonton. Sementara untuk pengukuran RT, C80 dan D50, dilakukan dengan menyediakan sumber suara mantap dengan tingkat $100 \mathrm{~dB}$ atau sumber respons impuls di depan. Sebagai ruang untuk rapat(konferensi), ruang yang memiliki dimensi $10 \mathrm{~m} \times 14 \mathrm{~m}$ diharapkan setiap peserta yang hadir akan menerima suara langsung dari sumber. Dari hasil pengukuran, diperoleh nilai parameter akustik ruang memiliki perbedaan nilai SPL antara posisi depan dan belakang mencapai lebih dari $8 \mathrm{~dB}$, sementara untuk nilai parameter waktu dengung 1,0-1,28 s, C80 sebesar 1-4 dB, dan D50 sebesar 41$55 \%$. Nilai ini memenuhi prasyarat sebagai ruang konferensi, namun perlu adanya perbaikan terhadap distribusi parameter SPL. Untuk itu perlu adanya perlakuan khusus terhadap distribusi SPL agar menjadi merata. Pada akhirnya, semua peserta akan merasa nyaman saat menghadiri pertemuan atau kegiatan yang dilakukan di ruang tersebut.
\end{abstract}

\begin{abstract}
Acoustic parameter value required for conference room is the loudness and clarity of votes received by each participant. To get the quantification of these parameters, the necessary measurements of the distribution of acoustic parameters include SPL, C80, D50, and RT. SPL distribution measurement is done by using the sound source berupawhite noise of loudspeakeryang placed in leadership positions (front) and the receiver (in this case microphones) in the viewing area. As for the measurement of RT, C80 and D50, is done by providing a source of steady sound level of $100 \mathrm{~dB}$ or front impulsdi response resources. As the space for meetings (conferences), the space has a dimension of $10 \mathrm{~m} \times 14 \mathrm{~m}$ are expected every participant will receive sound directly from the source. From the measurement results, the value of the acoustic parameter space has a different value of SPL between front and rear position reaches more than $8 \mathrm{~dB}$, while the reverberation time parameter values from 1.0 to $1.28 \mathrm{~s}, \mathrm{C} 80$ by $1-4 \mathrm{~dB}$ and $\mathrm{D} 50$ is $41-55 \%$. This value meets the prerequisites as a conference room, but the need for improvements to the distribution parameter SPL. For that we need special treatment to the distribution of SPL in order to be equitable. In the end, all participants will feel comfortable when attending meetings or activities performed in that space.
\end{abstract}

KATA KUNCI: parameter akustik ruang, ruang konferensi, SPL, waktu dengung, kejelasan suara http://dx.doi.org/10.12962/j24604682.v13i1.2133

\section{PENDAHULUAN}

Mendengar adalah sebuah proses kultural yang melibatkan banyak unsur. Selain unsur sumber dan pendengar, unsur ruang menjadi prasyarat mutlak agar yang didengarkan menjadi sesuai dengan apa sumbernya. Secara akustik, sebuah ruangan yang baik adalah ruangan yang mampu mengakomodasi kebutuhan dari sumber serta pendengar. Gambar 1 menunjukkan kondisi dari ruang sidang sebagai objek dalam penelitian.

Didalam melakukan penilaian terhadap kualitas akustik sebuah ruang, terdapat beberapa parameter akustik objektif yang dapat mewakili kondisi ruangan. Berdasarkan pada Ando [1, 2], parameter tersebut diantaranya adalah tingkat kekerasan

\footnotetext{
*E-MAIL: kangyatno@physics.its.ac.id.
}

(Listening Level/LL), waktu dengung sub-sekuen (Tsub), waktu tunda pantula dini (Initial Time delay Gap/ITDG), Korelasi silang antara sinyal telinga kiri dan kanan (Inter $\mathrm{Au}$ ral Cross-Correlation/IACC). Dari ke-empat parameter diatas, parameter 1,2 dan 3 adalah parameter yang berbasis atau berdimensi waktu (spektral/temporal), sementara parameter ke-4 adalah parameter yang berbasis pada ruang (spatial). Sementara berdasarkan Beranek, parameter akustik objektif yang digunakan untuk menilai kondisi akustik ruang diantaranya adalah sebaran tingkat kekerasan suara (Sound Presure Level/SPL), waktu dengung ruang, kejelasan suara serta efek stereo ruang.

Berdasarkan pada Beranek [3-5], Skalevic [6], kebutuhan parameter akustik dari ruang akan memiliki batas atau nilai beberapa parameter utama sesuai dengan fungsi. Tabel I menunjukkan besarnya perbandingan parameter akustik ruang sesuai dengan fungsinya. 


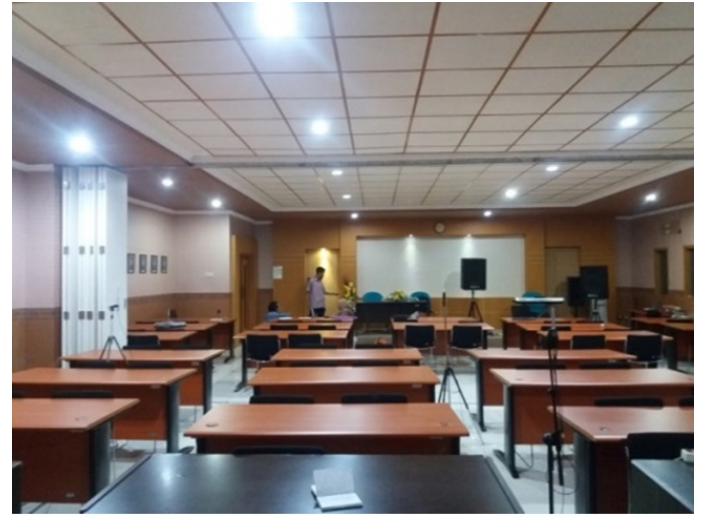

Gambar 1: Kondisi fisik dari ruang sidang Jurusan fisika FMIPA ITS.

TABEL I: Nilai parameter akustik ruang untuk ruang konser dan ruang rapat.

\begin{tabular}{lcc}
\hline \hline Parameter & Ruang konser & Pidato/rapat \\
\hline Waktu dengung ruang (RT) & $0,8-1,30 \mathrm{~s}$ & $1,301,83 \mathrm{~s}$ \\
Definisi/D50 & $>=65 \%$ & $45<\mathrm{D}<=60 \%$ \\
Clarity/C80 & $>6 \mathrm{~dB}$ & $-2<\mathrm{C}<+4$ \\
\hline \hline
\end{tabular}

Sebagai ruang untuk rapat dan konferensi, sebuah ruang sidang harus mampu memberikan kejelasan informasi kepada peserta. Parameter tersebut akan menentukan keakuratan informasi yang diterima pada saat acara berlangsung. Informasi tersebut dapat diperoleh apabila sebaran parameter karakteristik akustik ruang sesuai dengan kebutuhan dan fungsi ruang (Tabel I).

Untuk memenuhi kriteria sebagai ruang konferensi, maka bentuk ruang, furniture, serta sifat dan jenis material terhadap bunyi yang mengenainya harus mampu mendukung terhadap parameter yang diharapkan. Berdasarkan baberapa hal tersebut, maka dalam makalah ini dilakukan evaluasi kondisi akustik ruang serta upaya untuk memperbaiki, sehingga fungsinya sebagai ruang konferensi dan ruang rapat dapat terpenuhi. Parameter tersebut meliputi sebaran tingkat tekanan suara (Sound Presure Level/SPL), waktu dengung ruang (Reverberation Time/RT), dan kejelasan suara (Clarity/C80 dan Definition/D50).

\section{METODOLOGI}

Didalam melakukan upaya perbaikan kondisi akustik ruang agar sesuai dengan fungsinya, maka dilakukan beberapa langkah (tahapan), seperti tampak pada Gambar 2.

Untuk melakukan identifikasi terhadap parameter akustik dari ruang, pengukuran dimensi ruang menjadi hal yang penting. Hal ini dilakukan untuk mempermudah dalam menentukan posisi titik ukur serta prediksi terhadap sebaran parameter akustik. Untuk menghindari adanya dominasi komponen pantul (medan bebas), maka posisi titik ukur minimal $1 \mathrm{~m}$ dari dinding (permukaan pantul).

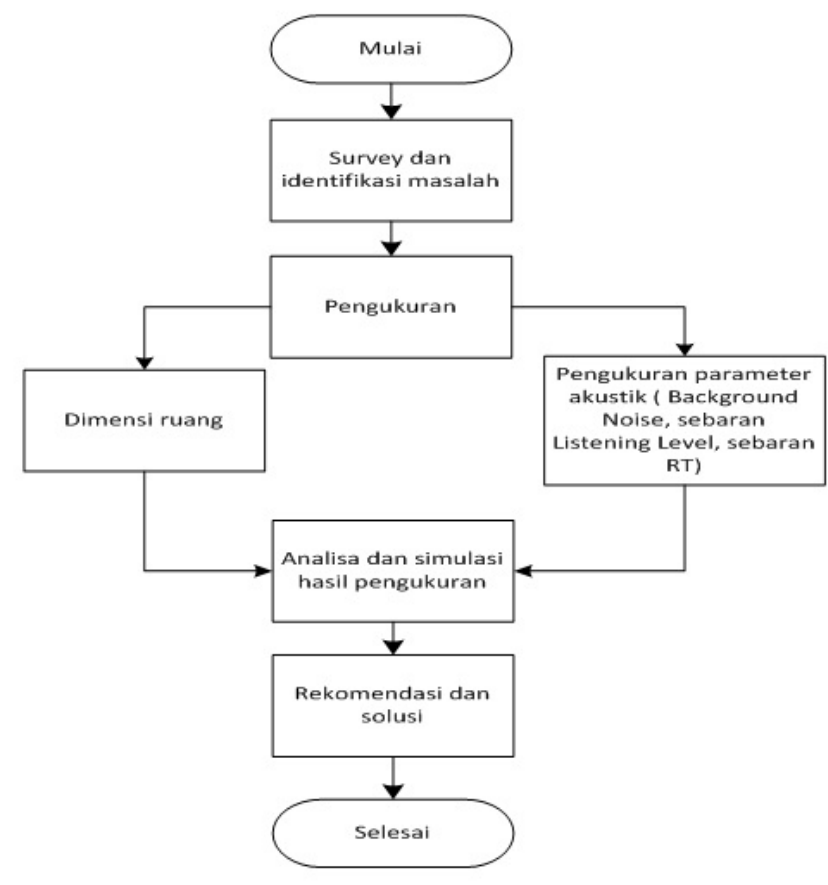

Gambar 2: Diagram alir pengambilan data.

Pengukuran sebaran parameter SPL dimaksudkan untuk mengetahui sebaran energi suara dalam ruang. Pengukuran sebaran SPL dilakukan dengan menggunakan sumber suara berupa white noise dengan SPL $100 \mathrm{~dB}$ yang berasal dari suara sistem tata suara elektronik (loudspeaker) yang berada di depan (posisi sesuai sumber suara ketika rapat dilakukan) serta pendengar berupa mikropon.Pengukuran waktu dengung dilakukan untuk mengetahui respon dari ruang, ketika sebuah sinyal suara dibunyikan dalam ruang. Dari pengukuran respon ruang (melalui respon impuls), secara objektif dapat diketahui parameter-parameter akustik dari ruang untuk beberapa posisi ruang. Parameter tersebut diantaranya adalah waktu dengung ruang, kejelasan suara vokal dan kejelasan suara musik (jika nantinya digunakan untuk ruang musik).

Setelah diperoleh sebaran parameter akustik dari ruang sidang, maka langkah berikutnya adalah mensimulasikan beberapa parameter akustik ruang termasuk didalamnya adalah material akustik dan bila mungkin diperlukan sistem tata suara elektronik. Tujuannya adalah untuk menjadikan ruang sidang sebagai ruang konferensi (ruang rapat). Gambar 3 menunjukkan dimensi dan denah pengukuran pada ruang sidang jurusan Fisika FMIPA ITS.

Dalam melakukan pengukuran, sumber suara dihasilkan melalui sistem tata suara elektronik (loudspeaker) serta penerima digunakan microphone. Sementara dalam melakukan analisis data, digunakan perangkat lunak berupa audio analyzer. 


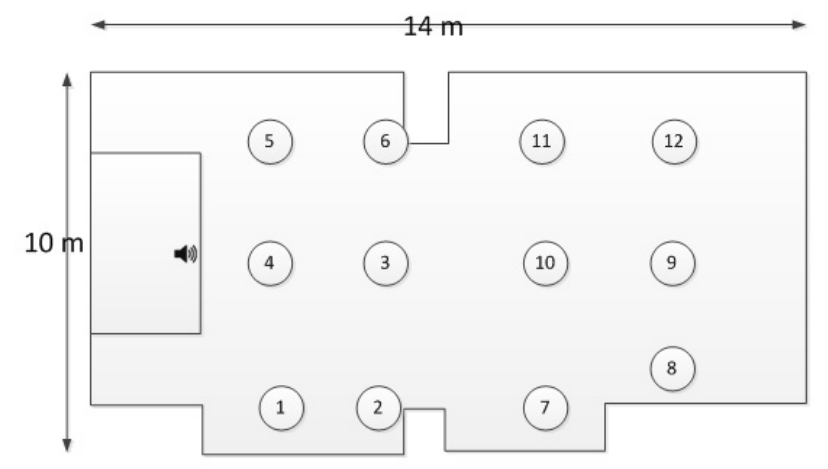

Gambar 3: Denah pengukuran di ruang sidang Jurusan Fisika FMIPA ITS.

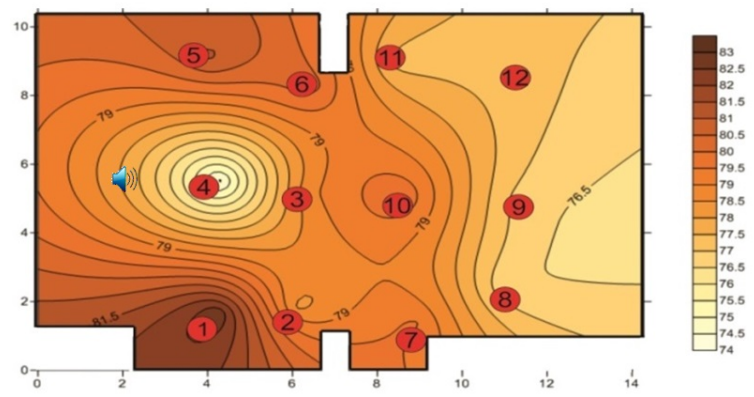

Gambar 4: Sebaran parameter akustik ruang pada kondisi eksisting.

\section{HASIL DAN ANALISIS}

Untuk memperbaiki kondisi akustik dari ruang sidang, maka perlu dilakukan pengukuran parameter akustik saat ini (sebelum dilakukan ) perbaikan. Parameter tersebut antara lain adalah sebaran SPL, sebaran waktu dengung ruang serta parameter kejelasan suara. Kondisi ini berfungsi sebagai data awal dalam melakukan perbaikan, baik melalui penambahan material ruang serta penambahan speaker. Dari hasil pengukuran, diperoleh data sebaran parameter seperti tampak pada Gambar 4.

Berdasarkan pada Gambar 4, terlihat bahwa nilai sebaran parameter akustik ruang yang kurang merata. Kondisi ini diakibatkan oleh jarak antara sumber suara (loudspeaker) dengan penerima. Bentuk ruang serta material yang ada dalam ruang. Kondisi eksisting dari ruang yang memanjang, menyebabkan suara yang diterima oleh pendengar pada bagian belakang akan sangat kecil, sehingga memiliki tingkat kekerasan suara yang jauh lebih kecil dengan posisi didepan. Sementara jenis dan sifat material yang ada dalam ruang menyebabkan pantulan suara yang dapat berakibat pada sebaran suara serta penyerapan suara. Selain berakibat pada sebaran SPL yang tidak merata, pantulan yang berkepanjangan dapat pula menyebabkan adanya dengung di dalam ruang menjadi panjang. Pada akhirnya, akibat adanya dengung tersebut menyebabkan kejelasan suara pada ruangan menjadi berkurang. Gambar 4 menunjukkan sebaran parameter akustik

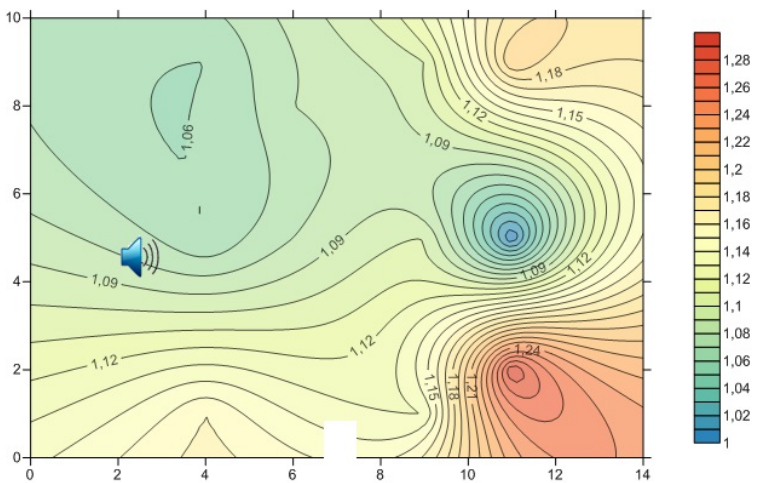

(a)

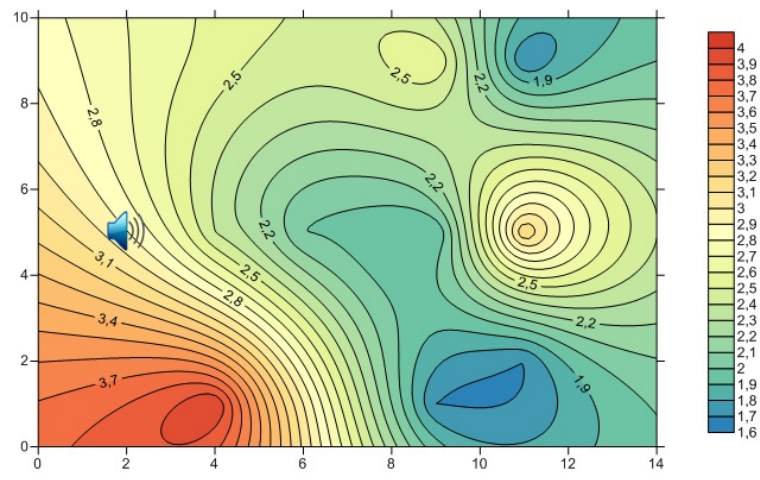

(b)

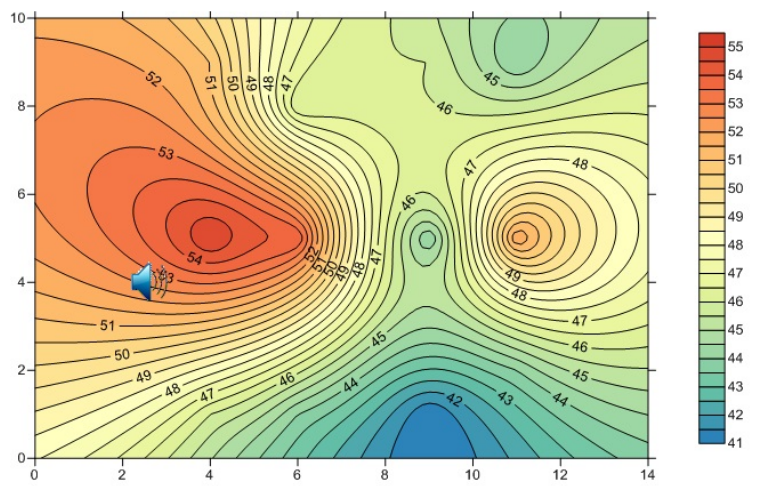

(c)

Gambar 5: Sebaran parameter RT, C80 dan D50.

waktu dengung, dan kejelasan suara ucap.

Berdasarkan pada Gambar 5, terlihat bahwa sebaran parameter dengung serta kejelasan suara pada ruangan ini memiliki sebaran yang tidak merata. Namun demikian, nilai ke-dua parameter tersebut masih berada dalam rentang parameter yang disepakati sebagai ruang konference (Tabel I), yaitu RT berada pada rentang $1 \mathrm{~s}$ sampai $1,28 \mathrm{~s}$, sementara nilai kejelasan suara C80 berada pada rentang 1,6 sampai dengan $4 \mathrm{~dB}$. Namun jika disejajarkan dengan sebaran parameter SPL yang cenderung keras pada bagian depan, menunjukkan bahwa kondisi ini menjadikan peserta yang dibagian belakang akan memperoleh informasi yang kurang optimum dengan perbe- 
daan yang lebih dari $8 \mathrm{~dB}$ dibandingkan dengan bagian depan (Gambar 3). Agar parameter akustik sebaran SPL dapat merata, dapat dilakukan dengan beberapa cara yang diantaranya adalah dengan menambahkan material pemantul pada bagian belakang dan atau dengan meberikan material penyerap suara di bagian sisi dinding bagian samping depan. Namun kondisi ini dapat berakibat pada tampilan visual menjadi berkurang. Sehingga cara lain yang dapat dilakukan adalah dengan menambahkan sistem tata suara elektronik (loudspeaker) pada posisi tertentu. Tujuannya adalah untuk memperbaiki distribusi sebaran SPL. Namun perlu adanya perencana yang lebih serius terkait jenis dan posisi dari loudspeaker yang harus ditambahkan. Pada akhirnya, penambahan loudspeaker tersebut benar-benar akan memperbaiki kondisi akustik ruang, bukan menjadikan masalah baru terhadap karakteristik akustik ruang, khususnya fungsi ruang sebagai ruang konferensi atau rapat.

\section{SIMPULAN}

Berdasarkan pada hasil pengukuran dan analisis terhadap parameter akustik ruang dari ruang sidang Jurusan Fisika
FMIPA, dapat diambil simpulan antara lain:

1. Sebagai ruang untuk konferensi (rapat), sebaran parameter akustik SPL kurang begitu merata, sehingga peserta yang berada di bagian belakang kurang dapat mendengarkan informasi dari pimpinan sidang.

2. Nilai parameter akustik dari ruang sidang berturut-turut adalah waktu dengung sebesar 1-1.28 s kejelasan suara ucap sebesar $41-55 \%$, serta kejelasan suara musik C80 sebesar 1,6-4 dB. Nilai sudah sesuai dengan prasyarat sebagai ruang konferensi.

\section{Ucapan Terima Kasih}

Penulis mengucapkan terima kasih kepada Jurusan Fisika FMIPA melalui LPPM ITS dengan no kontrak 034674/IT2.11/PN.08/2016 yang telah memberikan bantuan dana demi terlaksananya penelitian ini.
[1] Y. Ando, Architectural acoustics: Blending sound source, sound fields, and listener (Springer, 1998).

[2] Y. Ando, Opera house acoustics based on Subjective preference Theory (Springer, 2015).

[3] L. Beranek, How the sound; Concert and Opera House (Acoustics society of America, American Institute of Physics, 1996).

[4] L. Beranek, Concert Hall and Opera House; Musics, Acoustics and Architecture (edisi ke-2, Springer, 2004).
[5] L. Beranek, Journal Audio Engineering Society, 56(7/8) (2008).

[6] M. Skalevik, Reverberation Time- the mother of all room acoustical parameters, Baltic Nordic Acoustics Meeting, Norwegia, 2010.

[7] M.S. Ribeirio, Room Acoustic Quality Of A Multipurpose Hall: A Case Study, International conference: architectural acoustics and sound reinforcement, 2002. 